\title{
Combination of Caffeine and Liver Albumin Plus Protects against Smoking-Induced Liver Injury in Rats
}

\author{
Heba S. Shoukry ${ }^{a}$ b Maha M. Taher ${ }^{b}$ AbdAllah Enany ${ }^{b}$ Tarek Ahmed $^{b}$ \\ Ibrahim Hassan ${ }^{b}$ \\ aPhysiology Department, Faculty of Medicine, Cairo University, Cairo, Egypt; ${ }^{b}$ Pharmacology Department, \\ Faculty of Pharmacy, Modern Sciences and Arts University, October 6 University, Giza, Egypt
}

\section{Keywords}

Caffeine · Liver Albumin Plus · Smoking · Alpha-fetoprotein · Hypoxia-inducible factor

\section{Abstract \\ Background: A number of studies have revealed the hepa- toprotective effect of coffee and tea. However, the role of caffeine on smoking-induced liver injury is not well elucidat- ed. Liver Albumin Plus (LAP) is a liver supplement given in different liver diseases; to our knowledge, its role in smok- ing-induced liver injury is not clear. Objectives: This study aimed to find out the protective effect of caffeine and LAP alone and in combination in attenuation of smoking-in- duced liver injury. Methods: Thirty male albino rats were di- vided into a control group and a smoking group; the smok- ing group was then subdivided into a smoking group, a smoking + caffeine group, a smoking + LAP group, and a smoking + caffeine + LAP group. At the end of the experi- mental study, blood samples were collected for assessment of liver enzymes, alpha-fetoprotein (AFP), and interleukin 6, and livers were excised. Biochemical analysis of hydrogen}

peroxide $\left(\mathrm{H}_{2} \mathrm{O}_{2}\right)$, superoxide dismutase (SOD), and hypoxiainducible factor (HIF) as well as histological examination were done. Results: The results showed that smoking elevated liver enzymes, AFP, $\mathrm{H}_{2} \mathrm{O}_{2}$, and HIF and decreased SOD; histologically, deterioration of the liver was observed. On administration of caffeine, significant $(p<0.05)$ improvement in all measured parameters and preserved liver histological structure were observed, while intake of LAP alone showed some improvement. In combination, all liver parameters were improved and histological structure was preserved in contrast to each drug alone. Conclusion: It is better to give a combination of caffeine and LAP with cigarettes smoking to attenuate smoking-induced liver injury.

(c) 2019 The Author(s)
Published by S. Karger AG, Basel

\section{Introduction}

Caffeine (1,3,7-trimethylxanthine) is contained in many foods and beverages, such as coffee and tea. It is widely consumed as it acts as a central nervous system stimulator; moreover, it can be used clinically as a di-

\section{KARGER}

E-Mail karger@karger.com www.karger.com/dmj
(C) 2019 The Author(s)
Published by S. Karger AG, Basel Oper ar
This article is licensed under the Creative Commons AttributionNonCommercial-NoDerivatives 4.0 International License (CC BYNC-ND) (http://www.karger.com/Services/OpenAccessLicense). Usage and distribution for commercial purposes as well as any distribution of modified material requires written permission.
Heba S. Shoukry

Physiology Department, Faculty of Medicine, Cairo University

Al-Saray Street, El Manial

Cairo 11956 (Egypt)

E-Mail dean@kasralainy.edu.eg 
uretic, analgesic, and muscle relaxant [1]. Studies mentioned that caffeine may increase the production of free radicals that in turn increase lipid peroxidation [2]. Oxidative stress leads to oxidative modification of cellular proteins, such as receptors and transport systems [3]. However, caffeine was found to protect against cellular damage via the production of useful antioxidant products [4]. Caffeine nowadays is known for its hepatoprotective effect against toxic agents on the liver, as detected via improvement in liver functions [5]. Liver Albumin Plus (LAP) is an available medication in the market as it is widely used as a liver support medication in many liver diseases; however, few studies have been performed on LAP. A study performed on polynitroxyl albumin plus found that it may protect against liver injury caused by reactive oxygen species (ROS) as in cases of liver ischemia reperfusion via its antioxidant and anti-inflammatory effect [6]. Smoking causes a variety of hazardous effects on organs which are toxic, immunological, and oncogenic in nature. Moreover, smoking produces chemical substances that have cytotoxic effects, such as necroinflammation and fibrosis. Additionally, smoking increases the production of proinflammatory cytokines such as interleukin 1 (IL-1), IL-6, and tumor necrosis factor alpha (TNFa), leading to liver cell injury [7]. It was found that cigarette smoking was significantly associated with increased liver enzymes [8]. However, hepatologists have conventionally paid little attention to the injurious effects of cigarette smoke. In the United States, tobacco use was responsible for 467,000 deaths in 2005 [9]. According to Ghaly et al. [10], cigarette smoke exposure can result in degenerative changes in hepatocytes, cellular infiltration, periportal fibrosis, and congestion of both the central and portal veins. Evidence provided by Azzalini et al. [11] showed that cigarette smoke causes oxidative stress and apoptosis in the liver. Tobacco is known for its oncogenic effect in several organs, a number of studies showing that cigarette smoking is associated with an increased incidence of hepatocellular carcinoma in cirrhotic patients [12]. Hypoxiainducible factor (HIF) is a transcription factor that regulates a wide range of genes involved in cellular responses to hypoxia. HIF is a heterodimeric complex consisting of a $\beta$-subunit and an oxygen-sensitive $\alpha$-subunit. Increased expression of HIF is observed in many liver diseases [13]. A common feature of liver diseases is tissue hypoxia due to an imbalance between demand and supply [14], as oxygen consumption by hepatocytes and infiltrating inflammatory leukocytes is dramatically increased [15]. Interestingly, increased production of ROS is a common phenomenon in pathological liver conditions, and in turn they have also been shown to stabilize HIF [16]. The aim of this study was to find out the hepatoprotective effect of caffeine alone and in combination with LAP against the toxic effects of smoking. The focus of this paper was to predict the toxic and pathophysiological effects on human outcomes as animals can be used to predict human response to drugs and other chemicals.

\section{Materials and Methods}

Thirty male albino rats weighing $120-150 \mathrm{~g}$ were obtained and inbred, with veterinary care, in the Modern Sciences and Arts University animal house. Female rats were not included in this research due to the variable nature of female data caused by hormonal fluctuations associated with the female reproductive cycle. The animals were housed in wire mesh cages at room temperature with normal light-dark cycles and maintained on standard rat chow diet and tap water during the 4-week experimental period. They were allowed to acclimatize to their environment for 1 week before the start of the experiments, which were conducted in accordance with the ethical guidelines of the Faculty of Medicine, Cairo University. Animals were divided randomly into a control normal group (control group, $n=6$ ) and cigarette smoke-exposed rats (smoking group, $n=24$ ), the latter being subdivided into a cigarette smoke only-exposed group (smoking group, $n=6$ ), a cigarette smoke-exposed group with administration of caffeine (smoking + caffeine, $n=6$ ) in which caffeine was given at a dose of $100 \mathrm{mg} / \mathrm{kg} /$ day orally to the end of the experimental study [17], a cigarette smoke-exposed group with intake of LAP (smoking + LAP, $n=6$ ) in which LAP was given at a dose of $16 \mathrm{mg} /$ day/rat orally to the end of the experimental study, and a cigarette smoke-exposed group with administration of caffeine and LAP in the above-mentioned doses (smoking + caffeine + LAP, $n=6$ ).

At the end of the experimental period, blood samples were collected and rats were then sacrificed. Liver tissues were collected and sectioned for biochemical analysis, preserved in foil, and kept frozen at $-80^{\circ} \mathrm{C}$; the remaining tissues were preserved in formalin $10 \%$ for histological analysis.

\section{Cigarette Smoking Protocol}

Rats were exposed to cigarette smoke at a dose of five cigarettes/ day to the end of the experimental period (4 weeks); a 1-h interval was left between the burning of two cigarettes [17].

\section{Biochemical Measurements}

(1) Liver enzymes (aspartate transaminase, alanine transaminase, and alkaline phosphatase) using commercially available kits (BioMed, Cairo, Egypt). (2) Serum IL-6 (assessed via Elisa kit supplied by MyBio Source, USA), according to the manufacturer's instruction. (3) Serum alpha-fetoprotein (AFP) using commercially available kits (BioMed). (4) Detection of liver hydrogen peroxide $\left(\mathrm{H}_{2} \mathrm{O}_{2}\right)$ and superoxide dismutase (SOD) by polymerase chain reaction kits (BioMed). (5) Detection of liver HIF via Western blot kits supplied by Bio Basic Inc., Markham, ON, Canada. 
Table 1. Assessment of ALT and AST

\begin{tabular}{lcr}
\hline Group & \multicolumn{2}{l}{ Parameter } \\
\cline { 2 - 3 } & ALT & \multicolumn{1}{c}{ AST } \\
\hline Control & $13.67 \pm 1.12$ & $14.17 \pm 0.6$ \\
Smoking & $62.83 \pm 4.17^{\mathrm{a}}$ & $52.5 \pm 1.12^{\mathrm{a}}$ \\
Smoking + caffeine & $32 \pm 0.93^{\mathrm{a}, \mathrm{b}}$ & $30.17 \pm 0.79^{\mathrm{a}, \mathrm{b}}$ \\
Smoking + LAP & $31.67 \pm 0.88^{\mathrm{a}, \mathrm{b}}$ & $24 \pm 0.97^{\mathrm{a}-\mathrm{c}}$ \\
Smoking + caffeine + LAP & $21.33 \pm 0.8^{\mathrm{a}-\mathrm{d}}$ & $20 \pm 1.37^{\mathrm{a}-\mathrm{d}}$ \\
\hline
\end{tabular}

Values are expressed as mean \pm standard deviation for 6 rats per group. ALT, alanine transaminase; AST, aspartate transami-

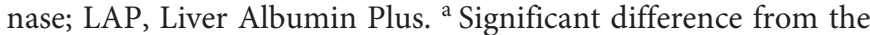
control group at $p<0.05$. ${ }^{\mathrm{b}}$ Significant difference from the smoking group at $p<0.05$. ' Significant difference from the smoking + caffeine group at $p<0.05 .{ }^{\mathrm{d}}$ Significant difference from the smoking + LAP group at $p<0.05$.

\section{Histological Analysis}

Liver tissue was fixed in a solution of $10 \%$ neutral buffered formalin, embedded in paraffin, sectioned at a thickness of $5 \mu \mathrm{m}$, and stained with hematoxylin and eosin for regular examination. The sections were analyzed using an Olympus BX51 microscope equipped with camera, with $\times 100$ magnification in all examined groups.

\section{Statistical Analysis}

Results are expressed as mean \pm standard deviation. Statistical significance was performed by one-way analysis of variance, used to make an analysis and sort out significant statistical differences, followed by Tukey-Kramer posttest. All groups showed normally distributed values and equal variances. The sample size was based on previous studies.

\section{Results}

\section{Biochemical Results}

Liver Enzymes. Liver enzymes were significantly elevated in the smoking group in comparison to the control normal nonsmoking group $(p<0.05)$. On administration of caffeine or LAP, significant improvement $(p<0.05)$ was detected in comparison to the smoking group. Combination of caffeine and LAP showed significant improvement in comparison to the smoking group and in comparison to each drug alone, but still elevation compared to the normal control group (Table 1).

Serum IL-6. IL-6 was significantly elevated in the smoking group in comparison to the control normal nonsmoking group $(p<0.05)$. On administration of caffeine or LAP, significant improvement $(p<0.05)$ was detected in comparison to the smoking group. Combination of
Table 2. Assessment of serum IL-6

\begin{tabular}{lc}
\hline Group & IL-6, pg/mL \\
\hline Control & $1.0 \pm 0.001$ \\
Smoking & $7.57 \pm 0.41^{\mathrm{a}}$ \\
Smoking + caffeine & $3.73 \pm 0.06^{\mathrm{a}, \mathrm{b}}$ \\
Smoking + LAP & $3.83 \pm 0.12^{\mathrm{a}, \mathrm{b}}$ \\
Smoking + caffeine + LAP & $2.31 \pm 0.11^{\mathrm{a}-\mathrm{d}}$ \\
\hline
\end{tabular}

Values are expressed as mean \pm standard deviation for 6 rats per group. IL-6, interleukin 6; LAP, Liver Albumin Plus a Significant difference from the control group at $p<0.05$. ${ }^{\mathrm{b}}$ Significant difference from the smoking group at $p<0.05$. ${ }^{\mathrm{c}}$ Significant difference from the smoking + caffeine group at $p<0.05$. ${ }^{\mathrm{d}}$ Significant difference from the smoking + LAP group at $p<0.05$.

Table 3. Assessment of serum AFP

\begin{tabular}{ll}
\hline Group & AFP, ng/mL \\
\hline Control & $0.53 \pm 0.02$ \\
Smoking & $0.96 \pm 0.03^{\mathrm{a}}$ \\
Smoking + caffeine & $0.68 \pm 0.01^{\mathrm{a}, \mathrm{b}}$ \\
Smoking + LAP & $0.71 \pm 0.03^{\mathrm{a}, \mathrm{b}}$ \\
Smoking + caffeine + LAP & $0.56 \pm 0.01^{\mathrm{b}-\mathrm{d}}$ \\
\hline
\end{tabular}

Values are expressed as mean \pm standard deviation for 6 rats per group. AFP, alpha-fetoprotein; LAP, Liver Albumin Plus. ${ }^{\text {a Sig- }}$ nificant difference from the control group at $p<0.05$. ${ }^{\mathrm{b}}$ Significant difference from the smoking group at $p<0.05$. ${ }^{c}$ Significant difference from the smoking + caffeine group at $p<0.05 .{ }^{\mathrm{d}}$ Significant difference from the smoking + LAP group at $p<0.05$.

caffeine and LAP showed significant improvement in comparison to the smoking group and in comparison to each drug alone, but still elevation compared to the normal control group (Table 2).

Serum AFP. AFP was significantly elevated in the smoking group in comparison to the control normal nonsmoking group $(p<0.05)$. On administration of caffeine or LAP, significant improvement $(p<0.05)$ was detected in comparison to the smoking group. Combination of caffeine and LAP showed significant improvement in comparison to the smoking group, and in comparison to each drug alone also normalization of its value was observed (Table 3).

Liver Expression Levels of $\mathrm{H}_{2} \mathrm{O}_{2}$ and SOD. A significant elevation in $\mathrm{H}_{2} \mathrm{O}_{2}$ and a significant decrease in SOD expression levels were detected in the smoking group in comparison to the control normal nonsmoking group 
Fig. 1. Assessment of liver expression levels of $\mathrm{H}_{2} \mathrm{O}_{2}$ detected by polymerase chain reaction. Values are expressed as mean \pm standard deviation. ${ }^{a}$ Significant difference from the control group at $p<0.05$. ${ }^{\mathrm{b}}$ Significant difference from the smoking group at $p<0.05$. ${ }^{c}$ Significant difference from the smoking + caffeine group at $p<0.05 .{ }^{\mathrm{d}}$ Significant difference from the smoking + LAP group at $p<0.05 . \mathrm{H}_{2} \mathrm{O}_{2}$, hydrogen peroxide; LAP, Liver Albumin Plus.

Fig. 2. Assessment of liver expression levels of SOD detected by polymerase chain reaction. Values are expressed as mean \pm standard deviation. ${ }^{a}$ Significant difference from the control group at $p<0.05$. ${ }^{\mathrm{b}}$ Significant difference from the smoking group at $p<0.05$. LAP, Liver Albumin Plus; SOD, superoxide dismutase.

Fig. 3. Assessment of liver expression levels of HIF detected by Western blot. Values are expressed as mean \pm standard deviation. a Significant difference from the control group at $p<0.05 .{ }^{\mathrm{b}}$ Significant difference from the smoking group at $p<0.05$. ' Significant difference from the smoking + caffeine group at $p<0.05$. ${ }^{\mathrm{d}}$ Significant difference from the smoking + LAP group at $p<$ 0.05. HIF, hypoxia-inducible factor; LAP, Liver Albumin Plus.
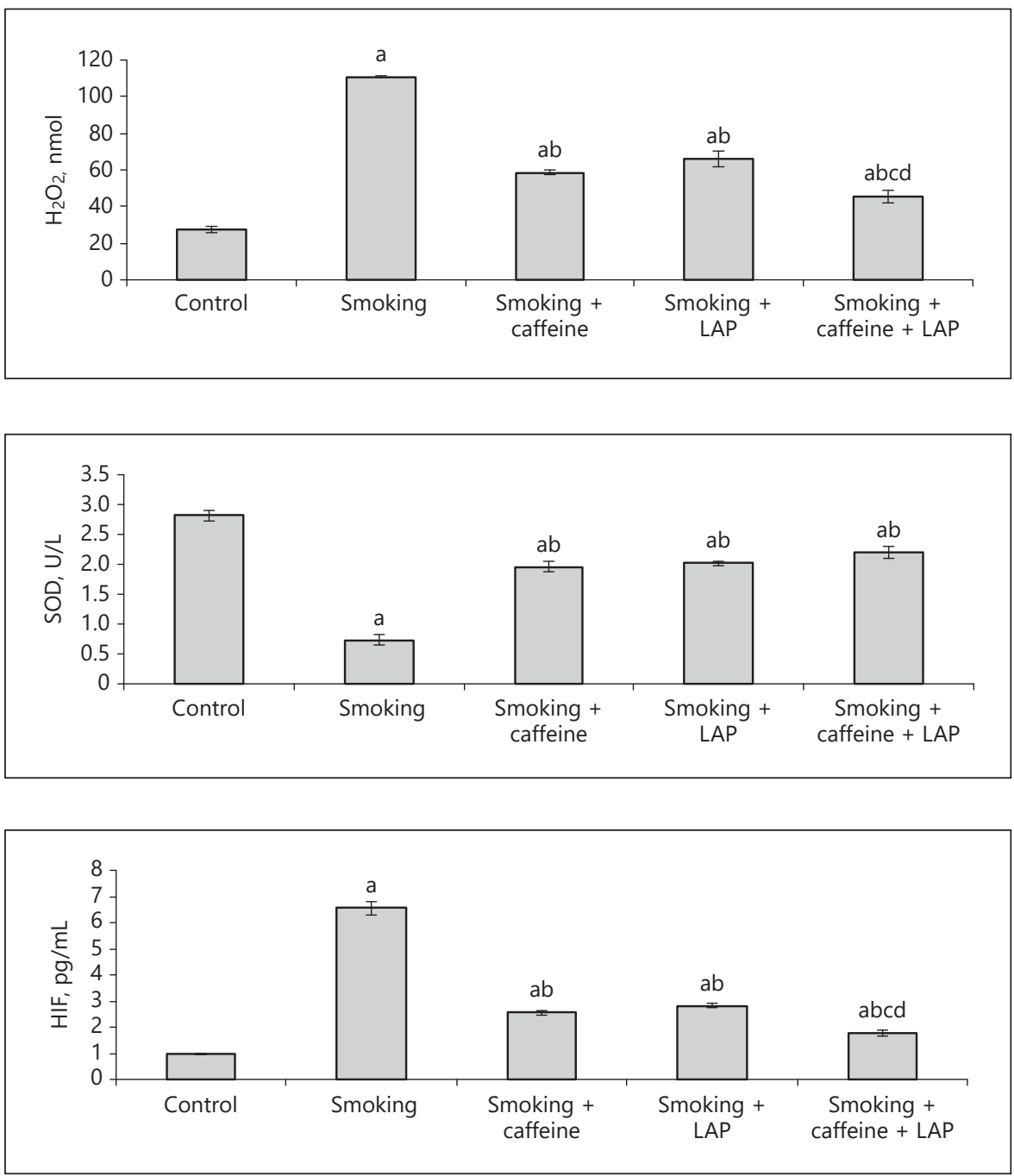

Table 4. Assessment of liver expression levels of HIF detected by Western blot

\begin{tabular}{lcc}
\hline \multirow{2}{*}{ Group } & \multicolumn{2}{l}{ Parameter } \\
\cline { 2 - 3 } & $\mathrm{H}_{2} \mathrm{O}_{2}$ & $\mathrm{SOD}$ \\
\hline Control & $27.42 \pm 1.58$ & $2.82 \pm 0.09$ \\
Smoking & $110.95 \pm 0.79^{\mathrm{a}}$ & $0.74 \pm 0.08^{\mathrm{a}}$ \\
Smoking + caffeine & $58.68 \pm 1.21^{\mathrm{a}, \mathrm{b}}$ & $1.96 \pm 0.09^{\mathrm{a}, \mathrm{b}}$ \\
Smoking + LAP & $66.23 \pm 4.31^{\mathrm{a}, \mathrm{b}}$ & $2.02 \pm 0.03^{\mathrm{a}, \mathrm{b}}$ \\
Smoking + caffeine + LAP & $45.4 \pm 3.63^{\mathrm{a}-\mathrm{d}}$ & $2.2 \pm 0.1^{\mathrm{a}, \mathrm{b}}$ \\
\hline
\end{tabular}

Values are expressed as mean \pm standard deviation for 6 rats per group. $\mathrm{H}_{2} \mathrm{O}_{2}$, hydrogen peroxide; HIF, hypoxia-inducible factor; LAP, Liver Albumin Plus; SOD, superoxide dismutase. ${ }^{\text {a }}$ Significant difference from the control group at $p<0.05$. ${ }^{\mathrm{b}}$ Significant difference from the smoking group at $p<0.05$. ' Significant difference from the smoking + caffeine group at $p<0.05$. ${ }^{\mathrm{d}}$ Significant difference from the smoking + LAP group at $p<0.05$. $(p<0.05)$. On administration of caffeine or LAP, significant improvement $(p<0.05)$ was detected in comparison to the smoking group. Combination of caffeine and LAP showed significant improvement in comparison to the smoking group and in $\mathrm{H}_{2} \mathrm{O}_{2}$ in comparison to each drug alone, as results returned to normal values and there was no significance in comparison to the normal control group (Table 4; Fig. 1, 2).

Liver Expression Levels of HIF. Liver expression levels of HIF were significantly elevated in the smoking group in comparison to the control normal nonsmoking group $(p<0.05)$. On administration of caffeine or LAP, significant improvement $(p<0.05)$ was detected in comparison to the smoking group. Combination of caffeine and LAP showed significant improvement in comparison to the smoking group and in comparison to each drug alone (Table 5; Fig. 3). 
Table 5. Liver expression levels of HIF

\begin{tabular}{ll}
\hline Group & HIF, pg/mL \\
\hline Control & $1.00 \pm 0.001$ \\
Smoking & $6.56 \pm 0.25^{\mathrm{a}}$ \\
Smoking + caffeine & $2.55 \pm 0.1^{\mathrm{a}, \mathrm{b}}$ \\
Smoking + LAP & $2.82 \pm 0.09^{\mathrm{a}, \mathrm{b}}$ \\
Smoking + caffeine + LAP & $1.78 \pm 0.12^{\mathrm{a}-\mathrm{d}}$ \\
\hline
\end{tabular}

Values are expressed as mean \pm standard deviation for 6 rats per group. HIF, hypoxia-inducible factor; LAP, Liver Albumin Plus. ${ }^{a}$ Significant difference from the control group at $p<0.05$. ${ }^{\mathrm{b}}$ Significant difference from the smoking group at $p<0.05$. ${ }^{\mathrm{c}} \mathrm{Sig}$ nificant difference from the smoking + caffeine group at $p<0.05$. ${ }^{\mathrm{d}}$ Significant difference from the smoking + LAP group at $p<0.05$.

\section{Histological Results}

The normal control group showed normal liver histological structure (Fig. 4a); the smoking group showed cytoplasmic vacuolation, congested central vein, inflammatory cellular infiltrate, and areas of necrosis all over the examined sections (Fig. 4b). On administration of caffeine, improvement was observed as decreased central vein congestion and decreased inflammatory cellular infiltrate in the portal tract while the liver still showed areas of necrosis (Fig. 4c). Unfortunately, LAP was not effective in the treatment of smoking effects on liver tissue, as cytoplasmic vacuolation was extensive and the liver showed areas of necrosis and inflammatory infiltration (Fig. 4d). Combination of caffeine and LAP mostly acquired normal architecture with normal-appearing hepatocytes (Fig. 4e).

\section{Discussion}

Smoking has nowadays become a widespread habit. To our knowledge, smoking affects all body organs and deteriorates their functions. The aim of the present study was to investigate the effects of cigarette smoking on rat liver and to search for potential protective effects of caffeine, which is a common nutritional beverage, and the protective effect of LAP as a liver supplement therapy alone and in combination on smoking-induced liver injury. The results of the present study showed that exposure of rats to cigarette smoke daily for 4 weeks resulted in deterioration of liver condition, as observed via increased serum levels of liver enzymes and serum AFP, which could be an indicator of liver failure, as mentioned by Varshney et al. [18], who reported that elevated serum
AFP is an indicator of acute liver failure. The data in this study were supported by histological examination, as was observed via increased liver inflammation and necrosis. These results are supported by Salahshoor et al. [19], who mentioned that smoking causes hepatocyte and central vein enlargement as well as elevated liver enzymes. In the present study, we searched for the mechanism of liver injury in the cigarette smoking group and observed elevated serum IL- 6 the in the exposed group. This result was mentioned by Sliwińska-Mossoń et al. [20], who detected a significant elevation in serum IL-6 in smoking patients and an increased expression of IL-6 in pancreatic acini with associated pancreatitis. In addition, Moszczyński et al. [21] mentioned that smoking increases the production of proinflammatory cytokines (IL-1, IL-6, and TNF- $\alpha$ ), resulting in liver cell injury. In addition, elevated liver oxidative stress was clear in the present study detected via elevated liver expression of $\mathrm{H}_{2} \mathrm{O}_{2}$ and decreased expression of SOD. It was mentioned by Battah et al. [22] that the smoke-exposed group showed increased mitochondrial numbers in hepatic cells and widening of their intermembrane space with loss of mitochondrial cristae; these findings pointed out that smoking displays cellular damage and oxidative stress resulting in ultrastructural liver changes. This increased oxidative stress could also be shown by Avti et al. [23], who explained that decreased liver levels of SOD with smokeless tobacco lead to inefficient removal of oxygen free radicals from cells, resulting in overaccumulation of ROS. Moreover, overproduction of ROS resulted in inhibition of expression levels of SOD. HIF is commonly known to be increased in most liver diseases, such as alcoholic and nonalcoholic liver diseases as well as ischemic liver injury [13]. In the present study, elevated liver expression levels of HIF in the smoking group could be explained by the findings of Tannahill et al. [24], who declared that during inflammation, succinate is increased and functions as an HIF activator. In addition, Guzy et al. [25] noticed that ROS has been shown to stabilize HIFs and that increased production of ROS is commonly found in most pathological liver conditions. We conclude from pervious data that elevated liver expression levels of HIF are a sign of liver injury and that they could be due to increased inflammatory conditions or overproduction of liver ROS. After the current study we think about using caffeine in attenuation of smokinginduced liver injury. Improvement was detected in the smoking group administered caffeine in the form of improvement of liver enzymes and AFP. These results are in accordance with the findings of Vitaglione et al. [26], who demonstrated that coffee consumption protects the liver 

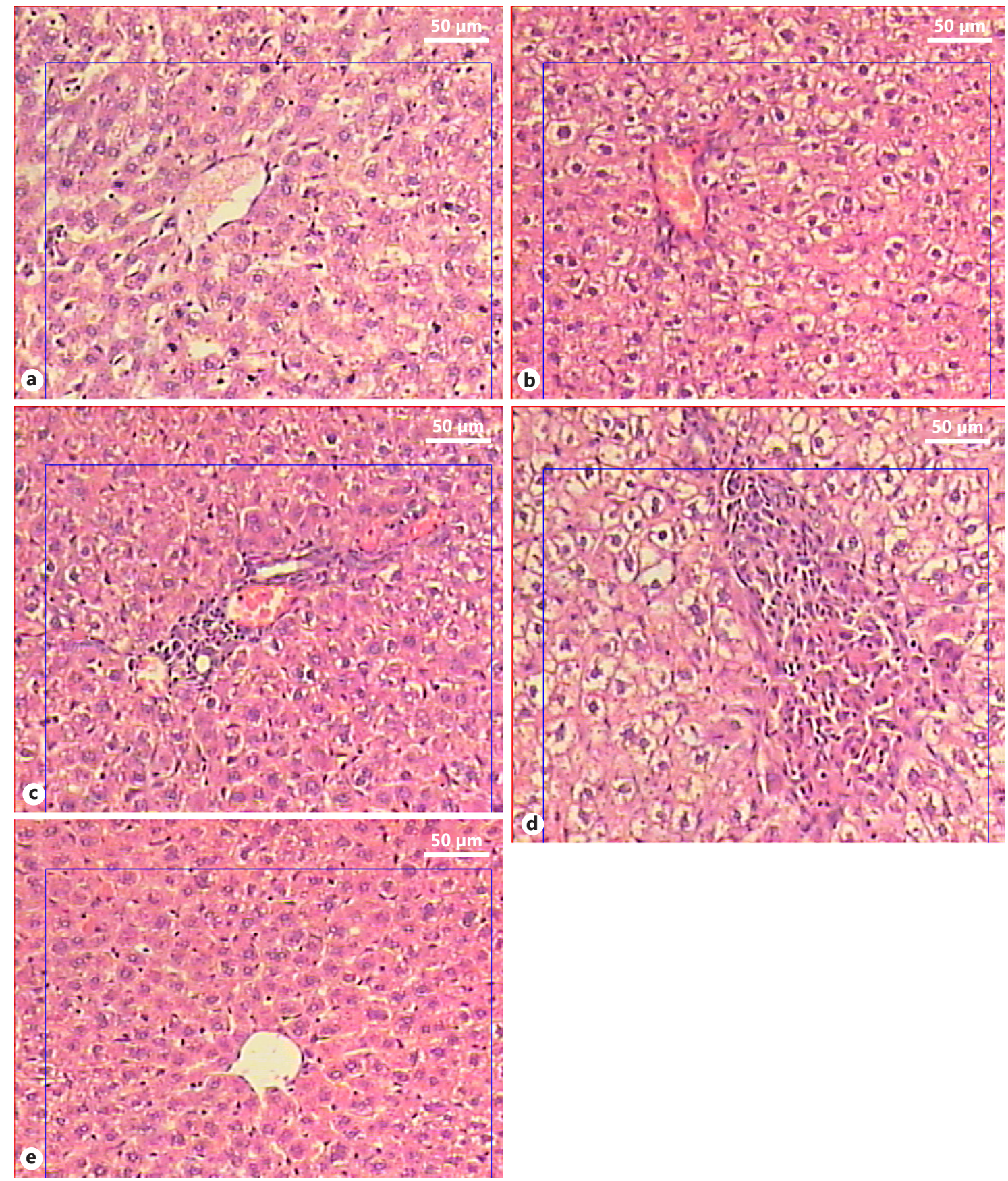

Fig. 4. Photomicrograph of liver sections stained with hematoxylin and eosin $(\times 100)$. a Normal control group showing normal liver histology, average-sized central vein, and pink cytoplasm with central vesicular nucleus. b Smoking group showing cytoplasmic vacuolation, congested central vein, inflammatory cellular infiltrate, and areas of necrosis all over the examined sections. c Smoking + caffeine group showing that caffeine treatment reduces the effects of smoking on the liver, seen as decreased central vein congestion, while the portal tract still shows inflammatory cellular infiltrate and areas of necrosis are still seen. $\mathbf{d}$ Smoking + LAP group: unfortunately, LAP was not effective in the treatment of smoking effects on liver tissue, as detected by extensive cytoplasmic vacuolation and areas of necrosis and inflammatory infiltration. e Smoking + caffeine + LAP group showed: great improvement was detected as liver tissue acquired normal architecture with normalappearing hepatocytes. LAP, Liver Albumin Plus. 
from damage by a high-fat diet. This effect could be mediated by a reduction in hepatic fat accumulation (through increased fatty acid $\beta$-oxidation), improvement of oxidative stress, and reduction of liver inflammation via decreased expression and concentrations of proteins and cytokines related to inflammation. The results are in accordance with the findings of Freedman et al. [27], who noticed, in a large prospective study of participants with advanced hepatitis $\mathrm{C}$, that regular administration of coffee resulted in lower rates of disease progression. Moreover, the present study showed moderate improvement in liver histological results. We explain the improvement in smoking-induced liver injury on administration of caffeine to be through caffeine's anti-inflammatory and antioxidant effects, as observed via decreased IL-6 and decreased expression level of $\mathrm{H}_{2} \mathrm{O}_{2}$. It was mentioned by Choi et al. [28] that treatment with coffee extract decreased the mRNA levels of IL- 6 in mice stimulated by lipopolysaccharide. Moreover, Amer et al. [29] declared that caffeine provided an antifibrogenic, anti-inflammatory, and antioxidant effect associated with improvement of hepatic histological structure from thioacetamide-induced hepatotoxicity. They explained their results by caffeine reducing serum levels of IL-6. Moreover, they hypothesized that the antioxidant effect of caffeine could be due to its modulation of antioxidant enzymes that results in reduction of ROS. This study is one of the few studies carried out on the effect of LAP on smoking-induced liv- er injury. Interestingly, in this study LAP intake in the smoking group improved all measured liver parameters; however, no improvement was seen in histological findings. In the present study, combination of caffeine and LAP showed much improvement in all measured parameters and also histological improvement.

In conclusion, combined administration of caffeine and LAP is able to attenuate smoking-induced liver injury.

\section{Acknowledgments}

The authors are thankful to the Biochemistry Department, Faculty of Medicine, Cairo University for performing biochemical measurements, and to Dr. Rophanda, histology doctor, for histology results.

\section{Statement of Ethics}

Animal experiments conformed to internationally accepted standards and to the ethical guidelines of the Faculty of Medicine, Cairo University.

\section{Disclosure Statement}

The authors have no conflicts of interest to declare.

\section{References}

1 Kolaylı S, Ocak M, Küçük M, Abbasoğlu R. Does caffeine bind to metal ions. Food Chem. 2004;84(3):383-8.

2 Dianzani MU, Muzio G, Biocca ME, Canuto RA. Lipid peroxidation in fatty liver induced by caffeine in rats. Int J Tissue React. 1991; 13(2):79-85.

3 Paşaoğlu H, Bulduk G, Oğüş E, Paşaoğlu A, Onalan G. Nitric oxide, lipid peroxides, and uric acid levels in pre-eclampsia and eclampsia. Tohoku J Exp Med. 2004 Feb;202(2):8792.

4 Krisko A, Kveder M, Pifat G. Effect of caffeine on oxidation susceptibility of human plasma low density lipoproteins. Clin Chim Acta. 2005 May;355(1-2):47-53.

5 Cachón AU, Quintal-Novelo C, Medina-Escobedo G, Castro-Aguilar G, Moo-Puc RE. Hepatoprotective Effect of Low Doses of Caffeine on CCl4-Induced Liver Damage in Rats. J Diet Suppl. 2017 Mar;14(2):158-72.

6 Blonder JM, McCalden TA, Hsia CJ, Billings RE. Polynitroxyl albumin plus tempol attenu- ates liver injury and inflammation after hepatic ischemia and reperfusion. Life Sci. 2000 Nov;67(26):3231-9.

7 El-Zayadi AR. Heavy smoking and liver. World J Gastroenterol. 2006 Oct;12(38): 6098-101.

8 Wannamethee SG, Shaper AG. Cigarette smoking and serum liver enzymes: the role of alcohol and inflammation. Ann Clin Biochem. 2010 Jul;47(Pt 4):321-6.

9 Danaei G, Ding EL, Mozaffarian D, Taylor B, Rehm J, Murray CJ, et al. The preventable causes of death in the United States: comparative risk assessment of dietary, lifestyle, and metabolic risk factors. PLoS Med. 2009 Apr; 6(4):e1000058.

10 Ghaly MA, Khedr EG, Abdel Aleem A. A comparative study of nicotine effect on the liver of albino rat. Egypt J Med. 2003;10:13044.

11 Azzalini L, Ferrer E, Ramalho LN, Moreno M, Domínguez M, Colmenero J, et al. Cigarette smoking exacerbates nonalcoholic fatty liver disease in obese rats. Hepatology. 2010 May; 51(5):1567-76.

12 Fujita Y, Shibata A, Ogimoto I, Kurozawa Y, Nose T, Yoshimura T, et al. The effect of interaction between hepatitis $\mathrm{C}$ virus and cigarette smoking on the risk of hepatocellular carcinoma. Br J Cancer. 2006 Mar;94(5):737-9.

13 Novo E, Povero D, Busletta C, Paternostro C, di Bonzo LV, Cannito S, et al. The biphasic nature of hypoxia-induced directional migration of activated human hepatic stellate cells. J Pathol. 2012 Mar;226(4):588-97.

14 Wilson GK, Brimacombe CL, Rowe IA, Reynolds GM, Fletcher NF, Stamataki Z, et al. A dual role for hypoxia inducible factor- $1 \alpha$ in the hepatitis $\mathrm{C}$ virus lifecycle and hepatoma migration. J Hepatol. 2012 Apr;56(4):803-9.

15 Campbell EL, Bruyninckx WJ, Kelly CJ, Glover LE, McNamee EN, Bowers BE, et al. Transmigrating neutrophils shape the mucosal microenvironment through localized oxygen depletion to influence resolution of inflammation. Immunity. 2014 Jan;40(1):66-77. 
16 Cramer T, Yamanishi Y, Clausen BE, Förster I, Pawlinski R, Mackman N, et al. HIF-1alpha is essential for myeloid cell-mediated inflammation. Cell. 2003 Mar;112(5):645-57.

17 Ogenyi SI, Choji TP, Chimezirim A, Onyemelukwe AO, Ngokere AA, Onwuasoanya UF, et al. Histological and biochemical effects of cigarette smoke on the liver of Wistar rats. Annu Res Rev Biol. 2015;7(2):119-25.

18 Varshney A, Gupta R, Verma SK, Ahmad S. Alpha-fetoprotein as a prognostic marker in acute liver failure: a pilot study. Trop Doct. 2017 Jul;47(3):202-5.

19 Salahshoor M, Mohamadian S, Kakabaraei S, Roshankhah S, Jalili C. Curcumin improves liver damage in male mice exposed to nicotine. J Tradit Complement Med. 2015 Jan; 6(2): 176-83.

20 Sliwińska-Mossoń M, Milnerowicz H, Jabłonowska M, Milnerowicz S, Nabzdyk S, Rabczyński J. The effect of smoking on expression of IL- 6 and antioxidants in pancreatic fluids and tissues in patients with chronic pancreatitis. Pancreatology. 2012 Jul-Aug; 12(4):295-304.
21 Moszczyński P, Zabiński Z, Moszczyński P Jr, Rutowski J, Słowiński S, Tabarowski Z. Immunological findings in cigarette smokers. Toxicol Lett. 2001 Jan;118(3):121-7.

22 Battah KA, Badran DH, Shraideh ZA. Effect of cigarette smoking on the structure of hepatocytes: TEM Study [Smokeless Tobacco Impairs the Antioxidant Defense in Liver, Lung, and Kidney of Rats]. Int J Morphol. 2016; 34(4):1239-44.

23 Avti PK, Kumar S, Pathak CM, Vaiphei K, Khanduja KL. Smokeless tobacco impairs the antioxidant defense in liver, lung, and kidney of rats. Toxicol Sci. 2006 Feb;89(2):547-53.

24 Tannahill GM, Curtis AM, Adamik J, Palsson-McDermott EM, McGettrick AF, Goel G, et al. Succinate is an inflammatory signal that induces IL-1 $\beta$ through HIF-1 $\alpha$. Nature. 2013 Apr;496(7444):238-42.
25 Guzy RD, Hoyos B, Robin E, Chen H, Liu L, Mansfield KD, et al. Mitochondrial complex III is required for hypoxia-induced ROS production and cellular oxygen sensing. Cell Metab. 2005 Jun;1(6):401-8

26 Vitaglione P, Morisco F, Mazzone G, Amoruso DC, Ribecco MT, Romano A, et al. Coffee reduces liver damage in a rat model of steatohepatitis: the underlying mechanisms and the role of polyphenols and melanoidins. Hepatology. 2010 Nov;52(5):1652-61.

27 Freedman ND, Everhart JE, Lindsay KL, Ghany MG, Curto TM, Shiffman ML, et al.; HALT-C Trial Group. Coffee intake is associated with lower rates of liver disease progression in chronic hepatitis C. Hepatology. 2009 Nov;50(5):1360-9.

28 Choi S, Jung S, Ko KS. Effects of Coffee Extracts with Different Roasting Degrees on Antioxidant and Anti-Inflammatory Systems in Mice. Nutrients. 2018 Mar;10(3):363.

29 Amer MG, Mazen NF, Mohamed AM. Caffeine intake decreases oxidative stress and inflammatory biomarkers in experimental liver diseases induced by thioacetamide: biochemical and histological study. Int J Immunopathol Pharmacol. 2017 Mar;30(1):13-24. 